\title{
La construcción social del sujeto migrante en América Latina. Prácticas, representaciones y categorías
}

\section{Bela Feldman-Bianco, Liliana Rivera Sánchez, Carolina Stefoni, Marta Inés Villa Martínez (Compiladoras)}

\author{
CLACSO - FLACSO - UAH, Buenos Aires, Quito, \\ Santiago, 2011, 366 págs. \\ María Gabriela Córdova Rivera \\ Universidad de Los Lagos, Santiago, Chile. Email: maria.cordova@ulagos.cl
}

\begin{abstract}
Una paradoja constitutiva de la cuestión migratoria a nivel mundial, tiene relación con el derecho humano a la libre circulación y la incapacidad política para avalarlo. Principalmente porque las garantías extendidas al emigrante no son las mismas que se ofrecen al inmigrante, y varían dependiendo de lo reconocido legítimamente por los Estados en su constitución y del interés, la conveniencia y la voluntad política de los gobiernos. Los que muchas veces tienden a politizar un problema social, para ganar adeptos o reducirlo netamente a su condición de trabajador, dejando su protección a merced del código laboral y la política de extranjería. No resulta del todo casual que en contextos de crisis económica, como la experimentada en Europa desde el 2008, se cierre la puerta a aquellos que contribuyeron al incremento del PIB en países como España, (mediante políticas restrictivas y la promoción de Planes de Retorno a sus países de origen) y se abra, (mediante políticas selectivas) solo aquellos migrantes especializados.
\end{abstract}

Los artículos agrupados en este libro además de ofrecer una panorámica de las migraciones en el contexto latinoamericano, dan cuenta de esta incongruencia que en términos fácticos tiende a dificultar el derecho "legítimo" a inmigrar, al no proveer dignas condiciones en los lugares de destino e identifica una serie de categorías a partir de las cuales construye al "sujeto migrante latinoamericano" desde los distintos actores y niveles.

El libro es el segundo trabajo de un grupo multidisciplinario de investigadores latinoamericanos que desde el 2004 y en el marco del Consejo Latinoamericano de Ciencias Sociales (CLACSO), viene dialogando acerca de la problemática migratoria en la región. A partir de una serie de reuniones anuales, el grupo de trabajo "migración, cultura y políticas", ha instalado el debate en torno a los desplazamientos que tienen lugar en América Latina y el Caribe, atendiendo a un enfoque de pensamiento crítico y a perspectivas teóricas, metodológicas y analíticas, que redefinen las categorías de clase, etnicidad y género en el estudio de los procesos migratorios.

Susana Novick, coordinadora del grupo de trabajo y responsable de la compilación del primer libro titulado, "Las migraciones en América Latina. Políticas, Culturas y Estrategias" publicado en 2008, rescata el valor y al mismo tiempo el desafío de esta iniciativa, pues no solo se trataría de "abordar las complejidades, tensiones, contradicciones y ambigüedades relacionadas con el fenómeno migratorio a nivel local, nacional o transnacional, así como sus transformaciones y sus efectos", sino también de levantar una agenda regional de reflexión e investigación en torno a esta temática. (Novick, 2008:9).

Un año más tarde, el grupo de investigadores, se da cita en la sede del Instituto Centroamericano de Estudios Sociales y Desarrollo, INCEDES en Ciudad de Guatemala, para profundizar en "la construcción social del migrante" y problematizar en torno a las categorías que definen al "sujeto migrante", distinguiendo entre los tipos de discursos y las estrategias que se erigen desde distintos agentes como el Estado y sus instituciones, la sociedad civil, los migrantes, y los propios investigadores. 
A partir de ese entonces se sitúan los lineamientos de esta segunda compilación de trabajos titulada: "La construcción social del sujeto migrante en América Latina. Prácticas, representaciones y categorías" que cuenta con el patrocinio de tres centros académicos: CLACSO, FLACSO-Ecuador y la Universidad Alberto Hurtado. Como lo afirman sus compiladoras, "con el objeto de contribuir a la comprensión del proceso de construcción del sujeto migrante latinoamericano, este libro reflexiona en torno a cómo las categorías son construidas en sus significados, en situaciones y circunstancias especificas y sobre qué tipo de relaciones de poder se entretejen en esas políticas de enunciación que categorizan al sujeto social de las migraciones y las movilidades humanas" (Feldman-Bianco, Rivera, Stefoni y Villa, 2011: 17).

Los artículos que integran esta nueva publicación, exponen el crecimiento del volumen del flujo migratorio desde los países en desarrollo de América Latina hacia los países industrializados, como una consecuencia de las asimetrías e inequidades en el orden económico internacional que, al facilitar la concentración de la riqueza, propicia mayores desigualdades entre las distintas áreas geográficas y sectores sociales. La particularidad de los diez artículos aquí contenidos, reside además en que, proporcionan al lector una panorámica de los procesos de migración Sur-Sur, desde "las representaciones sociales y las identidades en construcción y las relaciones del Estado con los movimientos sociales y las políticas migratorias" (Novick, 2008:12).

En términos generales, se pueden distinguir algunos ejes transversales a las reflexiones agrupadas en este libro. Marcos contextuales que operan como el hilo conductor de un relato que se configura desde distintos ámbitos (tanto receptores como emisores de migración) y se constituye como tal, mediante la articulación de sus partes como los procesos de re-democratización en la mayoría de los países estudiados, las políticas migratorias arraigadas principalmente en la seguridad nacional de los Estados y el control fronterizo, como parte y obra del Ministerio del Interior (con excepción de México, Ecuador y Brasil) y finalmente, la ausencia en la mayoría de los casos, de la concepción del migrante como sujeto de derechos y no exclusivamente como trabajador.

Dos partes constituyen este texto, la primera titulada "la perspectiva de los actores institucionales" concentra seis artículos que analizan desde el discurso más oficial, cómo es concebido el proceso migratorio y la construcción social del sujeto migrante desde las políticas de los Estados nacionales, las leyes y las políticas migratorias y cómo estas categorías elevadas desde posiciones de poder, inciden en la configuración misma del sujeto migrante latinoamericano y en la concepción de la migración como un problema social, propiamente tal.

En los tres primeros artículos de esta primera parte, dedicados a Argentina, Paraguay, Uruguay, y Chile se explicita a partir de un recorrido histórico, como ha sido abordada la problemática migratoria en los respectivos países, como se construyen categorías y políticas desde la adopción de un enfoque de derechos humanos que -ya sea por las condiciones propias de los pactos internacionales firmados o no-, entran en contradicción con la realidad practicada en cada uno de estos contextos y la categoría del inmigrado como peligroso y asunto de seguridad nacional. La figura del migrante como sinónimo de problema social se retoma desde dos perspectivas distintas en el cuarto y quinto apartado: como migrante político-conflictivo para en el caso de los refugiados cubanos en Estados Unidos y como un objeto de intervención donde confluyen representaciones en disputa en referidas a la construcción de la familia migrante. El artículo que cierra con esta primera sección, y que da apertura a la segunda parte del libro, releva otra dimensión de la producción del sujeto migrante, que surge de la confrontación y negociación entre los discursos etnográficos generados desde la academia y los institucionales, reparando en el migrante como "sujeto/actor" y "sujeto/objeto de investigación y en las políticas de atención de las instituciones"

La segunda parte, "la perspectiva de los sujetos migrantes", reúne cuatro textos relativos a la experiencia migratoria desde abajo. Desde la perspectiva de los mismos sujetos migrantes y su interacción con la política migratoria, abordando asimismo su capacidad de agenciamiento "en el contexto de las fuerzas de la estructura social e ideológica". Por un lado, a partir de estrategias socio-políticas ancladas en los movimientos sociales de los migrantes brasileros en Portugal, y por otro, como una estrategia económica de subsistencia de un colectivo de agricultores bolivianos y su devenir en la construcción de un sujeto migrante empoderado y reconocido por la agenda política local. La figura del auto reconocimiento de los migrantes con 
las categorías erigidas desde arriba y su imbricación en esta configuración, es abordado en los dos textos finales, específicamente con el uso de las categorías de "retornado" y "desplazado/refugiado".

El trabajo firmado por Eduardo Domenech, "Crónica de una amenaza anunciada. Inmigración e ilegalidad: visiones de Estado en la Argentina contemporánea" afirma que si bien la política migratoria de dicho país se ha reformulado y ha adquirido tintes más cercanos a ofrecer garantías a los extranjeros en el marco de los derechos humanos, esta mantiene un enfoque restrictivo y selectivo. Dicho enfoque sigue reproduciendo las categorías de legalidad/ilegalidad para interpelar principalmente a los inmigrantes fronterizos, y en función de estas, se conceden los derechos y garantías sociales, más específicamente, de la "regularidad de la residencia" en el territorio nacional. En estos términos, si "la principal preocupación del Estado, identifica la ilegalidad/irregularidad como el mayor problema", la nueva política migratoria de Argentina quedaría reducida a un proceso de legalización.

A partir de un recorrido histórico acerca del tratamiento oficial de la cuestión migratoria en Chile Carolina Stefoni, pone de manifiesto la "ambivalencia en la comprensión del migrante" desde la ley y política migratoria chilena. Esta ambivalencia se debería a que por un lado, se avanza en la protección de derechos puntuales y por otro, se sigue manteniendo una legislación que facilita la generación de migración irregular, todo esto en el marco la inexistencia de una "política explicita en materia migratoria". La construcción de las categorías "deseable/indeseable", "extranjero", e "irregular", para definir al sujeto migrante en determinados periodos, da cuenta de cómo la migración ha sido entendida, desde la legislación y la política, como un problema social y como se va configurando lo que la autora denomina como la política de la no política, para definir la situación contradictoria de Chile que sigue perpetuando la construcción de un sujeto excluido, por su condición de inmigrante.

En un contexto de integración regional, y libre circulación de bienes y servicios financieros, Susana Novick en su texto dedicado a las "Migraciones en el Cono Sur" analiza en mayor profundidad las posibilidades de las políticas, actores y los procesos de integración del tejido latinoamericano, concretamente desde Uruguay y Paraguay como miembros del Mercosur. Al igual que en los textos dedicados a Argentina y Chile, la migración tanto en Uruguay como en Paraguay es concebida como un problema social, existiendo en este último, características intrínsecas como cierta fragilidad institucional en la valoración de los principios democráticos, más propia de los años de sometimiento dictatorial, que la hacen más restrictiva y selectiva. Otro elemento interesante a destacar, está referido a los límites de la integración regional que en la práctica es entendida en términos puramente económicos.

En el cuarto artículo, Miriam Rodríguez, realiza un recorrido por la historia de las relaciones bilaterales entre y Cuba y Estados Unidos, a fin de caracterizar y distinguir al sujeto migrante cubano, del mexicano, y latinoamericano. Haciendo hincapié en la construcción social del migrante como un conflicto desde las instituciones, fundamenta históricamente, la categoría actual del migrante político y revela ciertos privilegios otorgados por la política inmigratoria que aplica Estados Unidos al migrante cubano, que lo favorecen por encima del migrante latino. En sus palabras: "Este (el migrante cubano) percibe que es un inmigrante deseado y siente cierta seguridad de contar con el apoyo para lograr su inserción en esta sociedad" (Feldman-Bianco, et.al, 2011: 174).

Por su parte, Gioconda Herrera, realiza un análisis del contexto el ecuatoriano, desde la perspectiva de género. En el marco de la nueva constitución ecuatoriana y el procedimiento de la legislación migratoria, desde el Ministerio de asuntos exteriores, la autora afirma que "el Estado se ha ocupado poco de las mujeres migrantes en tanto sujetos de derecho, pues no existen políticas explicitas dirigidas a ellas". La mujer migrante, en las políticas sociales de intervención se aborda de manera indirecta, mediante la construcción de la categoría de "familia migrante" como problema social, específicamente se la concibe como "familia rota". Como sujeto/objeto de intervención, esta categoría construida por el Estado, invisibiliza "la experiencia de las mujeres migrantes, sus problemas y vivencias" pues las reconocen solo en el rol de madres. La "familia migrante" se tiende a victimizar, atribuyéndole a la emigración femenina la responsabilidad del déficit en las tareas de cuidado y la desestructuración familiar en destino, una vez que esta se embarca en el proyecto migratorio. 
El último artículo de esta sección a cargo de Sergio Caggiano y Alicia Torres, titulado, "Negociando categorías, temas y problemas. Investigadores y organismos internacionales en el estudio de la migración indígena", nos acerca al ámbito más académico del tratamiento de la cuestión migratoria, al enfatizar en la reflexibilidad sobre quien ejerce la categorización migratoria, las fuentes y metodologías empleadas para la intervención. Específicamente y tal como lo señalan su artículo se dirige a debatir en torno a "la politicidad de las formas de construcción del sujeto migrante y a las distintas perspectivas que entran en juego" y como estas desde un ámbito universal o mas etnográfico se interpelan mutuamente.

Bela Feldman-Bianco en su estudio acerca de los procesos migratorios y la relación histórica entre Brasil y Portugal, abre la segunda sección del libro centrada en el "La perspectiva de los sujetos migrantes". Desde la condición del emigrante, su capacidad de organización en destino, y el apoyo institucional en origen, estudia los "caminos de la ciudadanía" a partir de experiencia de los brasileros en Lisboa. Examina tanto "las representaciones como las auto-representaciones" sobre este colectivo durante las movilizaciones por derechos en Lisboa iniciadas en los noventa y como estas inciden en la construcción social actual del inmigrante desde "el contexto de destino, específicamente de la era pos-Schengen". A partir del estudio de las movilizaciones por políticas públicas que incluyan los derechos de ciudadanía, de la Casa Brasil de Lisboa, la autora releva los logros conseguidos en cuanto a la formación de un agenda política inclusiva, debido principalmente a la "importancia de esa asociación y sus prácticas transnacionales en la lucha por los derechos de poblaciones desterritorializadas tanto en el escenario europeo como brasilero" (Ibid: 239)

El segundo texto de esta segunda sección es de Roberto Benencia y estudia el papel de un determinado colectivo de inmigrantes bolivianos, que se transformaron en actores sociales y sujetos de la agenda política en la Argentina. La posibilidad de estos migrantes bolivianos, de convertirse en sujeto de la agenda política, se da entre otras cosas gracias a la articulación entre la capacidad de agenciamiento de estos inmigrantes, el reconocimiento de estos productores de hortalizas, como un eslabón importante en la producción alimenticia de los cinturones verdes del área metropolitana de Buenos Aires bolivianos y la disposición e interese del gobierno local. El proceso de empoderamiento de estos sujetos/actores mediado por su capacidad organizativa y la aceptación pública, devino en la construcción de estos ya no solo como trabajadores sino además como sujetos sociales. Este tipo de agendismo politico generado desde abajo, se debe en palabras del autor a lazos fuertes y débiles, los primeros "les permitió a los inmigrantes el crecimiento económico en el lugar de destino", mientras los segundos les fueron de gran utilidad para "encarar las negociaciones con lideres políticos locales y técnicos privados"

Por su parte Liliana Rivera en su texto, “¿Quiénes son los retornados? Apuntes sobre el migrante retornado en el México contemporáneo" apela a la construcción social del "sujeto retornado" mexicano y como la interpretación de la figura del retorno esta como la finalización o conclusión definitiva de un ciclo, impide elevar una comprensión más amplia de este como un proceso más complejo. En sus palabras "El retorno no es un resultado previsible o definido por las condiciones locales, o solo por los capitales acumulados, sino que está condicionado a las intersecciones contingentes en contextos de retorno migratorio, contextos de destino y salida, circulaciones migratorias, mercados de trabajo y las dinámicas propias del capitalismo global" (Ibid: 311)

Finalmente, el artículo que cierra tanto esta sección como el libro, a cargo de Marta Villa aborda la problemática de los refugiados colombianos y del reconocimiento de estos con las categorías de desplazado y refugiado, en determinados contextos y situaciones, y como parte de una estrategia, de su lucha por la sobrevivencia, el reconocimiento y/o la inclusión social. Estas auto construcciones que los sujetos migrantes hacen de sí mismos sin duda interpelan y se contraponen con las denominaciones y parámetros "clasificatorios institucionales"

El texto es en definitiva una contribución consistente y basada en la investigación y análisis sistemático, a un problema central y no resuelto, respecto de los flujos migratorios contemporáneos. La paradoja de que el derecho a circular libremente, está sujeto por una parte al derecho a emigrar reconocido en la Declaración Universal de los Derechos Humanos, y las constituciones de la gran mayoría de los países receptores de inmigrantes, pero por otra, a la posibilidad (incierta) de inmigrar. La que está supeditada a la voluntad política de los países receptores representada en sus legislaciones y sistemas de regulación de la circulación de personas. Una paradoja que trae consecuencias negativas no solo para las condiciones de 
ingreso a los países de destino, sino también contribuye severamente a la degradación de las condiciones de asentamiento una vez que los migrantes han logrado traspasar la frontera.

$$
* * *
$$

Recibido: 05.03.2012

Aceptado: 28.03.2012 